\title{
Co-Designing an Immersive and Interactive Alcohol Resistance Training Tool Using 360-Degree Video
}

\author{
Patricia Bianca Lyk ${ }^{1}$, Gunver Majgaard ${ }^{1}$, Timo Dietrich ${ }^{2}$ and Christiane Stock ${ }^{3}$ \\ ${ }^{1}$ Embodied Systems for Robotics and Learning, Odense, Denmark \\ 2Social Marketing@ Griffith, Griffith University, Brisbane, Australia \\ ${ }^{3}$ Institute for Health and Nursing Science, Charité Berlin, Germany \\ pabl@mmmi.sdu.dk \\ gum@mmmi.sdu.dk \\ cstock@health.sdu.dk \\ t.dietrich@griffith.edu.au \\ DOI: $10.34190 / G B L 19.081$
}

\begin{abstract}
The presented design case gives an example of co-designing an interactive 360-degree simulation for alcohol prevention, where the user attends a party and creates her own experience through a number of choices. Overall, the application consists of 125 different movie sequences. The 360-degree simulation is experienced through VR glasses to provide an immersive and intense experience. As an example, the user can choose whether to drink alcohol or not, what type of alcohol and how often. The user is also faced with non-alcohol related choices such as the opportunity to help an intoxicated man, starting a fight or flirting with other guests. The alcohol intake among adolescents in Denmark is among the highest in Europe. Lately it has been found that peer pressure is the main reason why adolescents start drinking. The goal of the application is to give Danish adolescents (aged 15 to 17) a first-hand virtual experience with alcohol and some tools for recognizing and handling peer pressure, which they can use later in real life. The stakeholders in the co-design process consisted of 10 students (aged 18-28) studying film making and game design at Askov Højskole, Denmark, their teachers, alcohol experts from social services and researchers with expertise within health promotion, social marketing, virtual reality (VR), interaction design and game development. Additionally, 35 students from Askov Efterskole (aged 15-17) participated as actors and extras. This article describes the iterative design process of the application, containing exploration of key concepts, concepts design, prototype design and usability testing.
\end{abstract}

Keywords: virtual reality, 360-degree video, co-design, alcohol prevention

\section{Introduction}

This article describes the first part of the development of VR FestLab (ed. In English PartyLab). VR FestLab is a VR application, where adolescents can experiment with intake of alcohol without the physical risks this behaviour can lead to in real life. The user is invited to a virtual party, where they are continuously exposed to decision making scenarios. These choices shape the plot and thus the user creates her own experience. The application has a total of 125 different 360-degree movie sequences.

By using 360-degree video, the user gets surrounded by the constructed world and can get an immersive (VR), hands-on experience, which is central in a learning process (Kolb, 2012; Piaget, 2001).

The application uses the Google Cardboard platform (Vr.google.com, 2019). Google Cardboard is an inexpensive VR headset made of cardboard, where the user places her phone inside and together the phone and cardboard headset make up a simple VR headset. Once the application is finalised, it will be available free of charge on both Google Play (for android users) and App Store (for iOs devices). The application is targeted for school use, but with this solution the users can continue their exploration at home.

The project is done as a co-production with adolescents and other stakeholders with an empowerment-based living lab approach. The adolescents, involved in this project, will contribute with their experience about how young people behave and communicate in social contexts and how young people party in Denmark today. This contrasts with most alcohol prevention programmes. Often the target group - the adolescents - plays no or a very limited role in the development of teaching material for alcohol prevention. Instead, experts and researchers take the in the development (Dietrich et al., 2016); McKay et al., 2012a, 2012b; Vogl et al., 2009).

The project consists of five phases: Exploration of key concepts, concept design, prototype design, Innovation design and testing. This article describes phase one to three, focusing on the technical development and the design choices related to this. 


\section{Patricia Bianca Lyk et al.}

\section{Situating the design case}

The adolescents' alcohol consumption in Denmark is among the highest in Europe (European Monitoring Center on Alcohol and Drugs, 2016). Risky drinking may have a lot of negative consequences, for example higher risk of a wide variety of diseases (Barbor et al., 2010) and negative impact on school and education (Wechsler et al., 1994).

Previously, anti-alcohol campaigns have mainly been based on moral encouragement, scare campaigns, or presenting a lot of factual knowledge to the adolescents. It is common to these that they have mostly been ineffective because they have built on the wrong foundation (Falco, 1992; Faggiano et al., 2017). Recently, it has been found that the main reason why young people start drinking is peer pressure (Hendricks et al., 2015; Flay, 2000). This has led to better and more effective anti-alcohol campaigns.

Blurred Minds (Dietrich et al., in press) is an Australian alcohol prevention program. The program includes the world's first VR simulation, which aims to train adolescents' ability to withstand peer pressure. The application is made as a gamified party, where the user makes various choices along the way and depending on this, they experience different consequences.

In this project, a similar application is developed in a Danish context. It draws on the experience, the developers behind the Blurred Minds program made and the feedback they got from their users (Dietrich et al., in press). The development takes place in a co-design process, where one of the developers behind Blurred Minds is a part of the development group. The group also includes Askov Højskoles (folk school) film teacher, film students, game design teacher, game design students, alcohol experts from social services and researchers with expertise within health promotion, game design, VR and interaction design. 35 students, aged 14-18 years, from Askov Efterskole (continuation school) participated as actors and extras. The Højskole was chosen because it has students from all regions of Denmark, and therefore represents the user group in the possible way.

\section{Background}

In a constructivist view, learning happens most effectively when the learner is active and gets a first-hand experience with the concept that is to be learned (Piaget, 2001; Papert, 1993; Kolb, 2012). Unfortunately, this is not always directly possible. New technologies like VR can be helpful. VR can immerse the user and enables her to take charge and it is exactly when the learner takes charge, that the best learning takes place, according to Papert (1993).

\subsection{0 -degree video and VR}

360-degree video is video that has been recorded in all directions simultaneously. In this project GoPro Fusion is used (Gopro.com, 2019). When the video clip is played later, the user takes the position of the camera and has full control of the viewing direction. The video can be played in headsets such as Google Cardboad (Gopro.com, 2019) or Oculus Go (Oculus.com, 2019).

When talking about VR, immersion is very central. Murray (1997) compares immersion to being enclosed in water and therefore surrounded by another reality. Elmezeny et al. (2018) have investigated immersion in relation to 360-degree video by comparing it with traditional video formats and VR. They describe two main categories of immersion, narrative immersion, which is "... influenced by the setting, as well as by interplay of story, characters, and viewer integration" and technical immersion, which "... manifests through cues to direct the viewer's attention and cues to acknowledge the viewer as a part of the virtual environment."

\subsection{Experience based learning}

According to constructivism learning theory, learning is an active construction of knowledge rather than a transfer (Papert, 1993; Piaget, 1947; Kolb, 2012). Learning is constructed though interaction with the world and though this interaction mental schemas are constructed, from which we relate to the world.

Papert (1993) mentions computers as a key tool, when trying to make (new) learning more accessible. It is not always possible to let the learner interact with the concept that needs to be learned, in a real-world setting. But by making a simulated world, where the learner can experiment, set up hypothesis and test them, the learner can still get a first-hand experience. 


\section{Patricia Bianca Lyk et al.}

\section{Related work}

In an educational context VR can be used to give students a first-hand experience. In an earlier project VR and augmented reality (AR) teaching material about the solar system was co-designed with a $5^{\text {th }}$ grade and their teacher. The material consisted of a traditional compendium with text and pictures and a mobile application. Most pages had additional simulations (in AR or VR), which could be accessed through the application. For example the students were able to take a walk by the Barringer crater or study the planets orbits around the sun in a 3D simulation (Majgaard et al., 2017).

Because of VR's ability to give people a feeling of being present, it has been found that it is good for exposure therapy. Since 1997 VR has been used for treatment of posttraumatic stress disorder (PTSD). The patients have been exposed to trauma-relevant environments, which is carefully controlled and customized by a therapist (Rizzo et. al, 2015). VR has also proven to be beneficial for treatment of anxiety (Carl et. al. 2019).

The idea of letting the user create their own story through a number of choices is not new. In the book series 'Choose your Own Adventure' published by Bantam Books the reader is the central character. The reader faces two or three options for every few pages and depending of the readers choices the story unfolds in different ways (Kraft, 1981). The Netflix film Black Mirror: Bandersnatch (IMDb, 2019) is inspired from 'Choose your Own Adventure'. It is interactive, and the viewer makes decisions on behalf of the main character.

\section{Method}

The project is an iterative design process involving co-design. The Living Lab approach is used, which is defined as "a design research methodology aimed at co-creating innovation through the involvement of aware users in a real-life setting" (Dell'Era, C. and Landoni, P., 2014). This means that the users are co-creaters though the whole process, from the first conceptual development phase through prototyping to launch of the finished product.

The project will go through five phases, see figure below: Exploration of key concepts, concept design, prototype design, usability testing, innovation design and then testing. Currently, we are working on the prototype design.

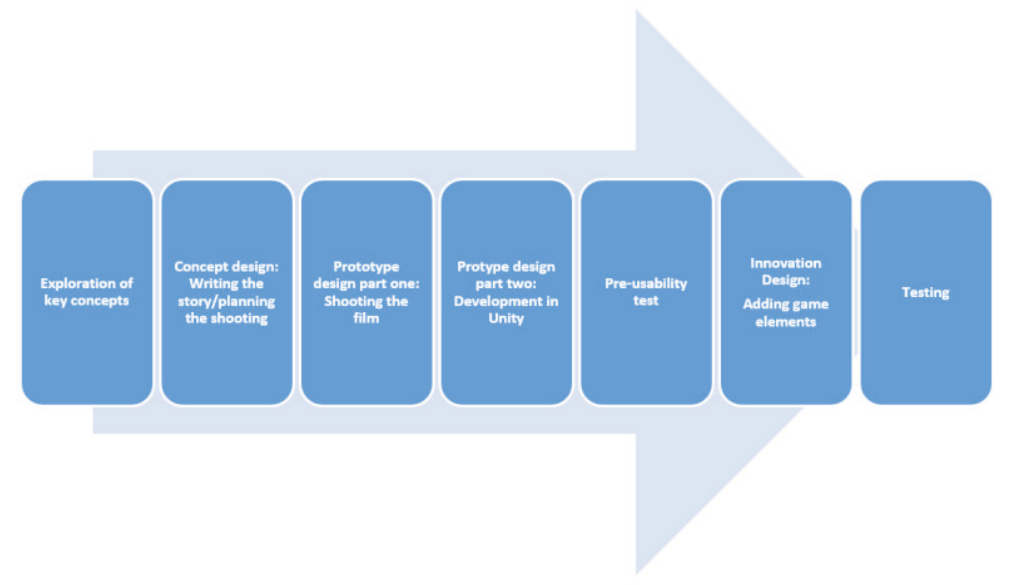

Figure 1: The phases of development (we are in the usability testing phase)

In the following we describe the design process for the first three phases.

\section{Exploration of key concepts}

The first iteration consisted of an exploration of the key concepts and testing the 360-degree camera.

To explore the key concepts, the participants from the development group were invited to test the Australian VR House Party application and were later asked to share and discuss their experiences. The developer of VR House Party shared his experiences from developing the application, summarized key about challenges they experienced and shared the feedback they had received from their users. 


\section{Patricia Bianca Lyk et al.}

From this point, a list of issues that the Danish application should contain was made. E.g., we wanted a more realistic calculation of the blood alcohol concentration (BAC). For example, in the Blurred Mind's VR House Party the user could pass out after as little as three drinks and it did not seem to matter whether you drank 3 drinks in a row or spread them over a longer period.

The new application should also be more consistent in giving instant feedback to the user. Several of the students from the development group had been confused, when they suddenly experienced a sudden end to the game. Additionally, an ending scene, which evaluates the evening, will be implemented.

It was also decided that the experience should contain more elements of gamification to boost further engagement and mini games based on popular drinking games, which were desired by the target group.

Among the feedback that the developer of VR House Party had received, was a great desire of users for more control over the experience as well as more choices. It was decided that the user should be placed in the middle of the party and be in charge of who to talk to, as it is exactly when the user is in charge, that the best learning takes place (Papert, 1993).

The users also commented on the distance from the user to other people in the application, which in some scenes were too far resulting in the user feeling distanced and like they were observing instead of being a part of the action. According to Sheik et al. (2016), the right distance between characters and the camera can increase emotional immersion.

\section{Prototype design: Writing the story/planning the shooting}

After the first session and brainstorming with the development team, the students from the film and game design course and their teachers started working on the manuscript. First, they decided on different types of personalities, made their personas and then flowcharts for each person.

Figure 2 shows the scene with the character Liam. Each oval represents a film sequence and the rhombus the choices the users gets. In this scene, the story is also affected by the gender, the user chose when she entered the simulation (red and blue).

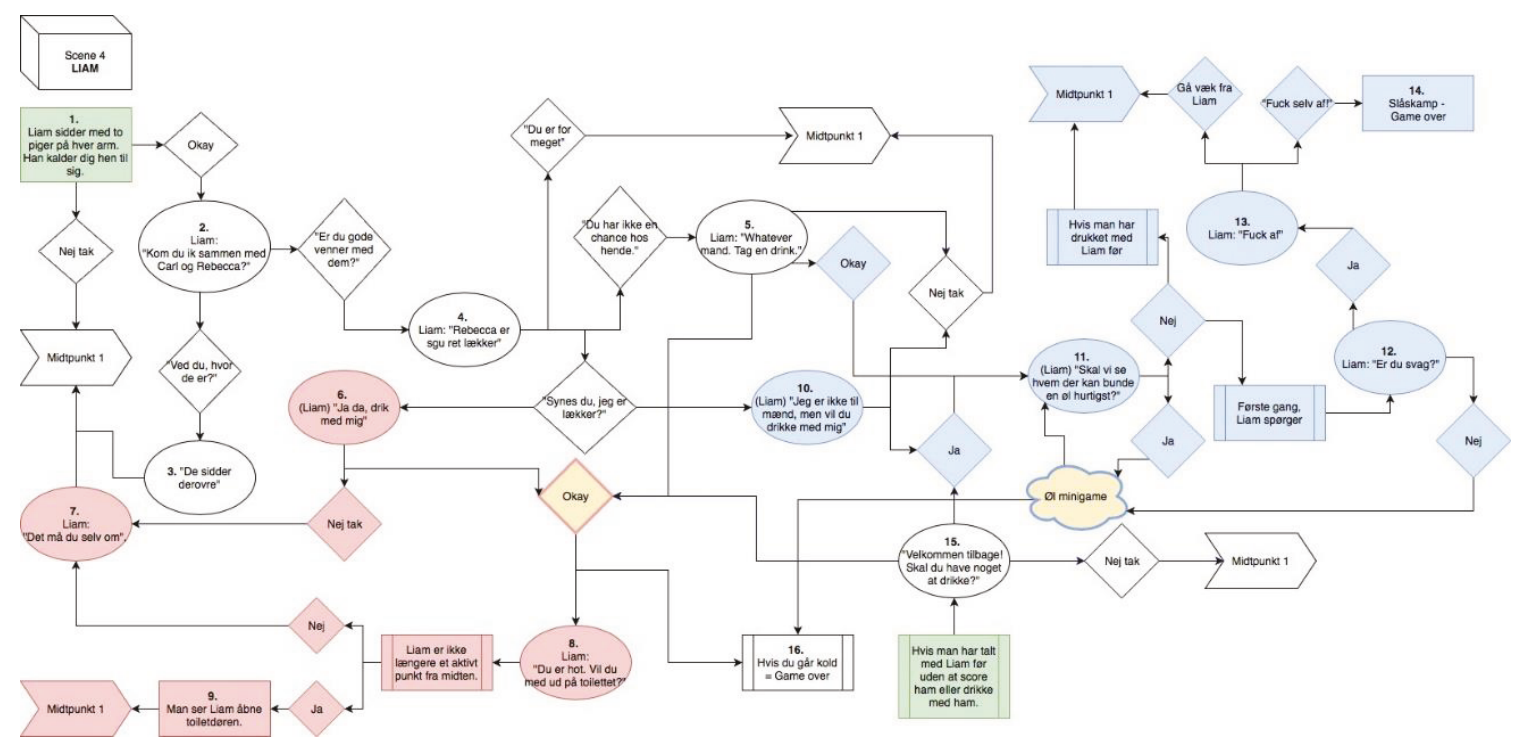

Figure 2: Flowchart of scene 4

The finished manuscript ended up with 11 scenes consisting of 125 different sequences. The students from the film course then casted the actors and extras from the Efterskole.

\section{Prototype design part one: Shooting the film}

To the recording of the 360-film was completed with a team of film school students. Different roles were assigned; sound technician, line-producer, stage designer and instructor (see figure 3). One of the researchers with VR experience was responsible for the operation of the camera. 


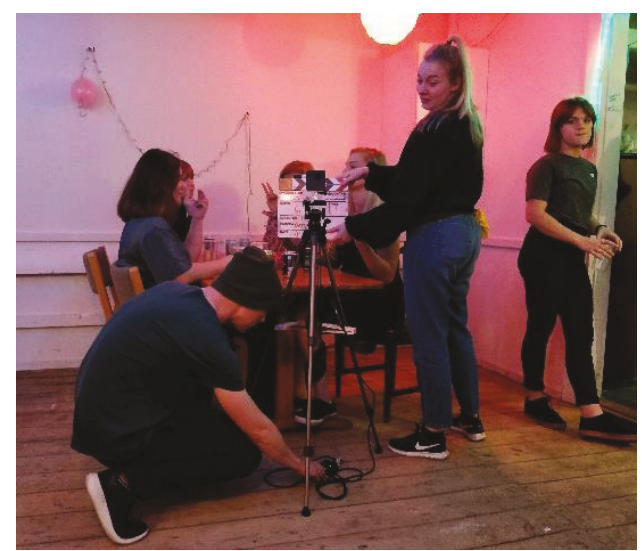

Figure 3: Students from Askov Højskole Film course getting ready to film

One of the challenges of filming 360-degree video is that the film team cannot be present in the room, where the recording takes place - otherwise they would be visible in the clips. Therefore, the camera was controlled through the GoPro application on a tablet (Gopro.com, 2019). This made also made it possible to check the setup in real time.

In some scenes the team took advantage of the fact the camera filmed two times 180-degree footage, which is only stitched together afterwards. It made it possible to record background and foreground in two different recordings, so all actors and extras did not need to be on the set all time.

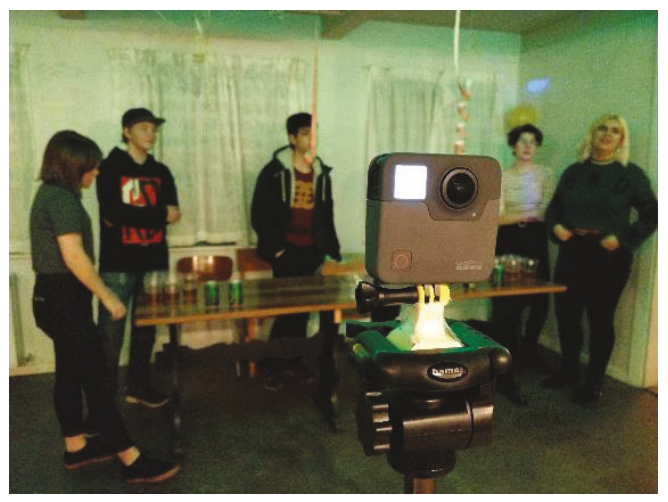

Figure 4: GoPro Fusion setup

Figure 4 shows the setup of the camera. Two out of the three days that were used to film, almost 9 hours were filmed without interruptions. The camera only holds battery for a couple of hours, so a power bank was connected and placed in a bag, since a wire to a power outlet would have been visible in the recordings.

In the middle of the tripod the extern microphone was attached. GoPro Fusion does record audio, but the quality is not good enough for this project.

\section{Prototype design part two: Development in Unity}

\subsection{Development in Unity}

The recordings were stitched together afterwards, edited, sound and movie were combined and then the clips got implemented in Unity.

For each scene in the manuscript, a scene in Unity was made. In figure 5, scene 4 the character Liam is seen. In the bottom the flowchart is placed to maintain the overview. Each of the black circles is a sphere with a movie clip. 
Patricia Bianca Lyk et al.

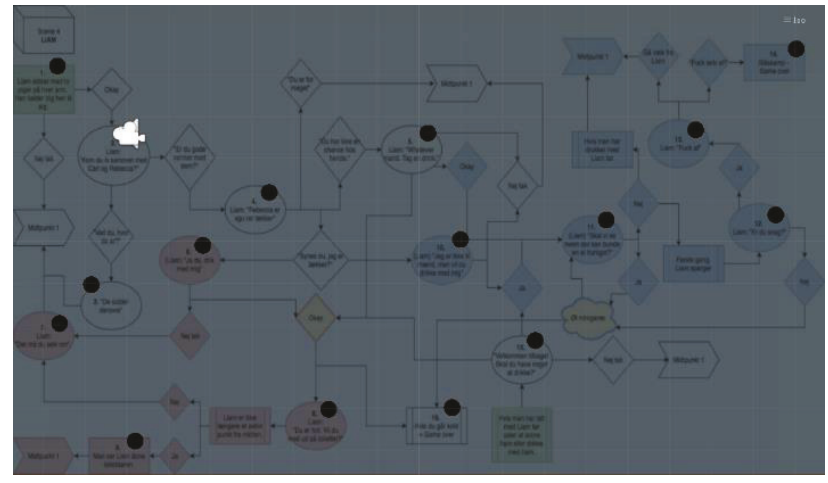

Figure 5: Scene 4 with Liam in Unity

The spheres have a specific material, which makes the video play on the inside of it, see figure 6 . By placing the camera and thus the user in the middle of the sphere, she will be surrounded by the video and get an immersive experience.

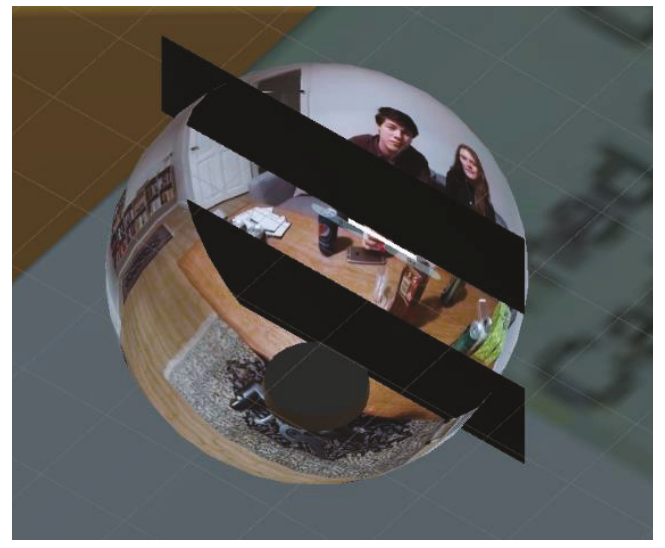

Figure 6: Video playing on the inside of a sphere

The spheres have a canvas and on this the buttons that make up the interaction and links between the clips are placed. They are not visible from the start, but when the video clip is almost finished, the different options for the user are shown. The user now chooses from a list of two to six options. She does this by staring at the button for about 1 second. First a small animation appears to indicate that the button is clickable and then - if she keeps staring - the button will be clicked. The click calls the function SphereChanger if the option leads to a new clip within the same scene and otherwise the script SceneChanger if the clip leads to a new clip in another scene.

To calculate the BAC, the chosen gender and average weight for a 16-year-old female/male and a game time is used. One minute in real time corresponds to 30 minutes in the game. The time is shown at the top of the screen and is always visible. The BAC is also shown here. It looks like a classic game health bar and shows the BAC in percent, see figure $7.100 \%$ green is sober, and it then gets more and more red as the user gets drunk. $100 \%$ red corresponds to a BAC at 2, which is very high and results in blackout. When the user chooses to take an alcoholic drink the script BACCalculation is called. This script calculates the current BAC and updates the user interface (UI). It uses the correct algorithm for BAC calculation (Becker \& Nielsen, 2019).

\section{BAC calculation algorithm:}

Female: Alcohol in gram / (body Weight in $\mathrm{kg} \times 60 \%)-(0,15 \times$ hours from drinking start) = BAC Male: Alcohol in gram / (body Weight in $\mathrm{kg} \times 70 \%)-(0,15 \times$ hours from drinking start) = BAC

The BAC bar is updated continuously, so it is visible to the user that the BAC decreases over time. 


\section{Patricia Bianca Lyk et al.}

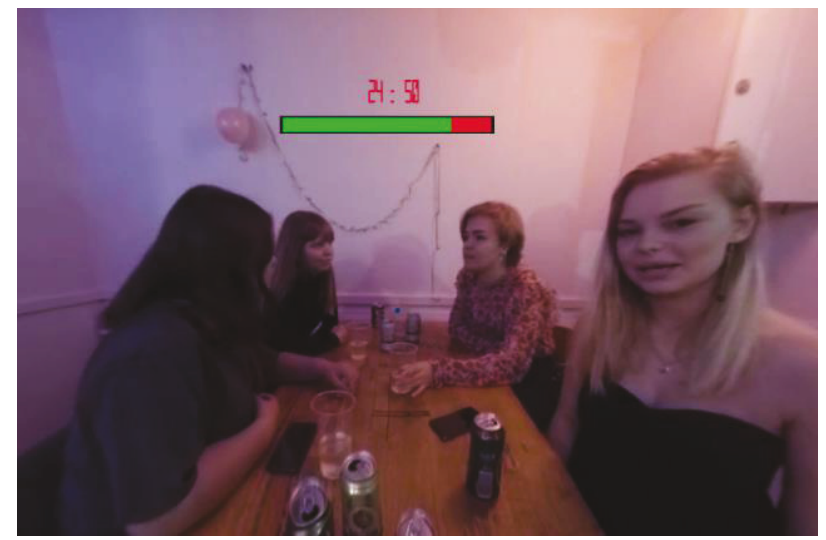

Figure 7: UI: Digital clock and BAC bar

While developing the first edition of the prototype, the game design students from Askov Højskole started working on mini games for the application. The mini games will be implemented later.

\section{Pre-usability test}

When the basic functionality was done a (pre)usability test was made. The goal of this test was primarily to find bugs, evaluate the interaction and UI and get ideas for gamification of the app.

Four students from Askov Game design course, that in the meantime had enrolled new students (so no one of these knew the project before the test), volunteered. They were aged 21-24 and therefore older than our target group, but for the purpose of a usability test of game elements and potential improvements as well as obtaining ideas for additional gamification elements they were suitable.

Each of them first tried the application for about 10 minutes under passive observation and afterwards they were interviewed in pairs. This was chosen to make them feel more confident and feel that they could talk more openly. Additionally, it could come in handy when talking about future gamification of the application because the students are used to brainstorming together and often pairs seem to get better ideas than individuals (Fullerton, 2014). The downside of making interviews in pairs is of cause dominant respondents, which can influence the other.

None of the students knew the purpose of the BAC bar before they had their first alcoholic drink and one of them did not understand the connection between drinking alcohol and the bar decreasing until he was almost finished playing. It was suggested that the bar should have a caption for example "Per Mille Meter" or the symbol for per thousand. The green/red colors of the bar made two of the participants think of a classic health bar and as a consequence of that they did not really want to drink alcohol since it would decrease their "health" /"life". This might limit student's experimentation in the app, which is the opposite of what we want - the students should experiment as much as possible in this safe environment. This involves both "good" and "bad" experiences with alcohol as our hypothesis is that experiences in the app will give students knowledge and tools they can later apply in these situations in real life. According to Papert (1993) the natural learning path contains false theories, which students learn as much from as they do from the true ones. Therefore, it is important that they feel that they can experiment freely and do not feel that drinking alcohol in the application is a (completely) unwanted act.

As a solution to this issue one of the participants suggested making the bar all white, because this would be more neutral and most likely not directly make the users think of "loosing life" like in a game. Furthermore, they suggested to make the decrease of the BAC over time more visible. For example, only show the decrease on the bar when a scene ended so that the decrease would be bigger. He also mentioned that adding an animation could make it even more visible and more fun to look at.

The association between the BAC bar and a health bar made one of the participants search for a clear goal "... like in a game". He was uncertain of what to do in the simulation and mostly what he was expected to do. He and the other participant, he was interviewed with, discussed this issue. They were aware of the fact that the simulation was not a game, but the BAC bar made them feel like they needed to "stay alive" to a certain point 


\section{Patricia Bianca Lyk et al.}

to face a challenge they did not know yet. One of them suggested that the goal of the application should be clearer, for example a short explanation in the start menu. The main use of the application will at a later point be in schools, where it will be placed into a didactic context, so in that situation it might not be a problem. But the application will also be available on Google Play and App Store and in that context the purpose must be clear.

It was also suggested to change the position of the BAC bar and the digital clock. One of the participants felt that the digital clock (at the top of the screen right in the middle, above the BAC bar) amounted to a pressure. He instead suggested to place the clock at the bottom of the screen in the right side, where clocks normally according to him - are placed in games.

The participants expressed a desire for an opportunity to lower the BAC by other causes than time, for example drinking water or going to the bathroom to pee. But drinking water or going to the bathroom will not reduce BAC and therefore it will not be implemented.

The gaze interaction worked well according to the participants. They understood how to make choices and praised the interaction. They, of course, have a lot of experience with games (and VR), which is probably not the case with the target group.

It was also suggested to add an animation or sound effects when the user drinks and throws up. This could give the user a clear feedback and let them know what is happening, which, according to the students was not always obvious. They also mentioned giving the user warnings, when they are close to passing out. It could be done with a blurry effect or an animation of blinking slowly.

The participants all got caught up by the story and wanted to experience more. Two students described a feeling of "being there" at the party. One of them said that it was especially in the center point, where the user stands in the middle of the party and can choose whom to go talk to. This is interesting because at this point, the user is standing by himself or herself and only observing, which is not an ideal situation for immersion (Elmezeny et al., 2018). The explanation for this could be, that it is at those points in the story that they feel most in control.

Minor bugs were also found, for example wrong placement of buttons and a line though the picture sometimes.

Summary of major key points in the usability test:

- BAC bar: clarification of purpose, virtual position and introducing animations

- Clarifications of goals and purpose: What is expected of the user?

- Gaze interaction works well

- Potential of immersion is realised

\section{Next step}

The next step is to correct the bugs found in the test, redesigning the UI, implementing the mini games, adding game elements to guide the user and to design ending scenes, which evaluate the evening. Furthermore, the simulation should contain more gamification. When this is done the application will be tested on the target group, again with focus on usability etc. This will probably lead to more redesign. Finally, the application will be tested in a randomized controlled trial to clarify the effect - will adolescents have more skills to resist peer pressure to drink after having used this application?

\section{Summary and conclusion}

This article has described the first phases of co-designing the interactive 360-degree simulation for alcohol prevention, VR FestLab. The design process began with exploration of key concepts and concept design in the development group, followed by design of prototype involving development of flowcharts, writing of manuscript, filming and development in Unity. The application ended up consisting of 125 movie clips. The clips the user meets and in which order depends on the choices the user makes, but also gender and current BAC. We learned that flowcharts are a great help, when filming a larger story with multiple paths. Without the flowcharts we would have lost track and we would not have been able to shoot all the clips in just one weekend. The flowcharts were also a big help, when the clips were implemented in Unity. 


\section{Patricia Bianca Lyk et al.}

The prototype was pre-usability tested. The test showed that the application has potential for immersing users. The users felt presence, and some had a feeling of "being there" at the party. Furthermore, we learned that the purpose and goal of the application needs to be clearer to the user. Especially when using game elements and that the purpose is not to win or complete (like in a game).

\section{Acknowledgements}

This research received funding (ID: 122827) from TrygFonden (Danish Safety Foundation).

\section{References}

Barbor T. et al. (2010). Alco-hol: No ordinary commodity. New York: Oxford University Press

Becker \& Nielsen (2019). Alkoholpromille, beregning. Retrieved from https://www.sundhed.dk/borger/patienthaandbogen/psyke/sygdomme/alkohol/alkoholpromille-beregning/

Blurredminds.com.au. (2019). blurredminds / Social marketing program designed for students to have hands on experience while learning about alcohol and drugs. [online] Available at: https://blurredminds.com.au/[Accessed 29 Apr. 2019].

Carl, E. et al. (2019). Virtual reality exposure therapy for anxiety and related disorders: A meta-analysis of randomized controlled trials. Journal of Anxiety Disorders, 61, pp.27-36.

Dell'Era, C. and Landoni, P. (2014). Living Lab: A Methodology between User-Centred Design and Participatory Design. Creativity and Innovation Management, 23(2), pp.137-154.

Dietrich, T. et al. (2016). Co-designing social marketing programs. Journal of Social Marketing, 6(1), pp.41-61.

Dietrich, T., Rundle-Thiele, S., Kubacki, K., Durl, J., Gullo, M., Arli, D., \& Connor, J. (in press). Virtual Reality in Social Marketing: A Process Evaluation Marketing Intelligence \& Planning.

Elmezeny, A., Edenhofer, N. and Wimmer, J. (2018). Immersive storytelling in 360-degree videos: An analysis of interplay between narrative and technical immersion. Journal for Virtual Worlds Research, 11(1).

European Monitoring Centre for Alcohol and Drugs (2016). ESPAD report 2015: results from the European School Survey Project on Alcohol and Other Drugs. European Monitoring Centre for Alcohol and Drugs

Faggiano F. et al. (2017) Universal school-based prevention for illicit drug use. Cochrane Database Syst Reviews. CD003020.

Falco, M., (1992). The making of a drug-free America: Programs that work. New York: Random House

Flay, B. (2000). Approaches to substance use prevention utilizing school curriculum plus environment change. Addictive Behavior, 25(6), 861-885.

Fullerton, T. (2014). Game design workshop. 3rd ed. CRC Press.

Gopro.com. (2019). GoPro Fusion | The most versatile 360 action camera ever. [online] Available at: https://shop.gopro.com/EMEA/cameras/fusion/CHDHZ-103-master.html [Accessed 29 Apr. 2019].

Hendricks, G., Savahl, S., Florence, M. (2015). Adolescent peer pressure, leisure boredom, and substance use in low-income Cape Town communities. Social Behavior and Personality, 43(1), 99-109.

IMDb. (2019). Black Mirror: Bandersnatch (2018) - IMDb. [online] Available at: https://www.imdb.com/title/tt9495224/ [Accessed 29 Apr. 2019].

Kolb, D. (2012). Experiential learning - Experience as the source of learning and development. Samfundslitteratur.

Kraft, S. (1981). He chose his own adventure. New York: The Day.

Majgaard, G. et al. (2017). Seeing the Unseen-Spatial Visualization of the Solar System with Physical Prototypes and Augmented Reality. International Journal of Designs for Learning, 8(2).

McKay, M. et al. (2012a), "Framing health messages for adolescents: should we use objective time periods, temporal benchmarks, or both?", Journal of Youth Studies, 15(3), pp.351-368.

McKay, M. et al. (2012b), "Reducing the harm from adolescent alcohol consumption: results from an adapted version of SHAHRP in Northern Ireland", Journal of Substance Use, 17(2), pp.98-121.

Milgram, P. et al. (1994). Augmented reality: A class of displays on the reality-virtuality continuum. Telemanipulator and Telepresence Technologies. 2351. 10.1117/12.197321.

Murray, J. (1997). Hamlet on the holodeck: The Future of Narrative in Cyberspace. New York: The Free Press.

Oculus.com. (2019). Oculus Go: Selvstændigt VR-headset / Oculus. [online] Available at: https://www.oculus.com/go/?locale=da DK [Accessed 29 Apr. 2019].

Papert, S. (1993). Mindstorms: Children, Computers, and Powerful Ideas. New York: Basic Books.

Piaget, J. (1947). The Psychology of intelligence, in Routledge Classics in 2001.

Rizzo, A. et al. (2015). Virtual Reality Exposure for PTSD Due to Military Combat and Terrorist Attacks. Journal of Contemporary Psychotherapy, 45(4), pp.255-264

Sheikh, A. et al. (2016). Directing attention in 360-degree video. UK: BBC Research and Development.

Unity.com. (2019). Unity - Unity. [online] Unity. Available at: https://unity.com/ [Accessed 29 Apr. 2019].

Vogl, L. et al. (2009). A computerized harm minimization prevention program for alcohol misuse and related harms: randomized controlled trial. Addiction, 104(4), pp.564-575.

Vr.google.com. (2019). Google Cardboard - Google VR. [online] Available at: https://vr.google.com/cardboard/ [Accessed 29 Apr. 2019].

Wechsler, H. et al. (1994). Health and behavioral consequences of binge drinking in college: A National survey of students at 140 campuses. Journal of the American Medical Association, 272(21), 1672-1677. 


\section{Biographies}

\section{Conference and Programme Chairs}
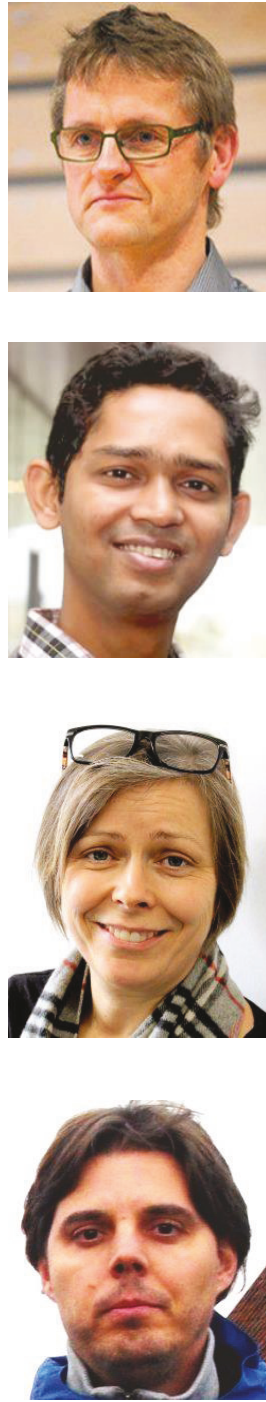

Lars Elbæk (PhD) is an Associate Professor at the Department of Sports Science and Clinical Biomechanics at the University of Southern Denmark and coordinator of the Sports Science Innovation and entrepreneurship program. He has worked with business innovation in the project "Play and Learning - Kids'n Tweens Lifestyle". He has through projects and his PhD in-depth knowledge and experience of interaction design and design research in sports, adapted physical activity, play approaches and pervasive computing. He has worked with NGO's, public institutions and private companies.

Md. Saifuddin Khalid is an Associate Professor in digital design and movement at University of Southern Denmark. He is also an external lecturer at the department of digitalization of Copenhagen Business School. With a background in the fields of computer science (BSC \& $\mathrm{MSc}$ ), business informatics (BSc), human-centered communication and informatics (PhD), Khalid works on IT systems' development, integration, and adoption processes. His research contributes in the multi-disciplinary fields of interaction design, service design, educational technology, diffusion research, health informatics and sports science. He received best teacher award 2016 at the Faculty of Humanities, Aalborg University, Denmark.

Gunver Majgaard (PhD) is Associate Professor at Embodied Systems for Robotics and Learning, Mærsk Mc-Kinney, University of Southern Denmark. She holds PhD in Robotics and Learning processes, which focused on design of educational tools and learning processes. The research focused on usage of physical-digital media and children as codesigners. Her research interests are technology in emerging technologies such as Mixed Reality; design of digital educational tools; game-based learning; participatory design processes; learning processes; didactical design; program and curriculum development. She has developed the engineering program Learning and Experience Technology.

Andrea Valente is Associate Professor with a background in computer graphics from Torino University in Italy, where he worked with formal languages, code mobility and objectoriented type systems (during the $\mathrm{PhD}$ ). He is currently researching educational tools for teaching Computer Science and other abstract concepts for elementary schools (the c-cards project and paper Turing machines). One of the goals of his research is to have simple toys (tangibles) to visualize and concretely operate with theoretical concepts like information or computation. Other areas of interest are e-learning especially in child education, real-time web systems and social media, formal methods and software engineering.

\section{Key Note Speakers}

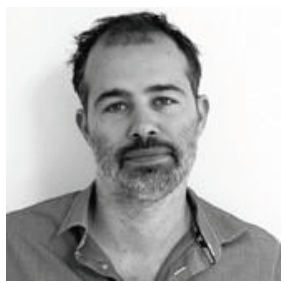

Simon Egenfeldt-Nielsen (PhD, Psychologist) is CEO of Serious Games Interactive, which he founded in 2006. Today it has around 15 employees. He has studied, researched and worked with computer games for +15 years. Over the years he has been involved in developing +150 games for different clients including Maersk, Metro, Opel, and World Bank. He has been involved in developing several award-winning series like Global Conflicts and Playing History. He has been involved in +10 primarily European research projects within game-based learning.

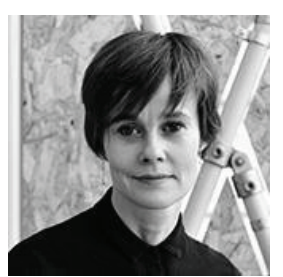

Helle Marie Skovsbjerg is the first Danish professor in play and is employed at the Design School Kolding. Her research focuses on the mood perspectives of play; a concept created through empirical work with children. Currently Helle Marie is investigating the unique Danish DNA for designing play and therefore contributing with knowledge of designing game-based learning. 
Reproduced with permission of copyright owner. Further reproduction prohibited without permission. 